\title{
Does Anxiety Symptomatology Affect Bullying Behavior in Children and Adolescents with ADHD?
}

\author{
Nuttorn Pityaratstian ${ }^{1}$ (D) . Jirada Prasartpornsirichoke ${ }^{1}$
}

Accepted: 3 February 2022 / Published online: 16 February 2022

(c) The Author(s) 2022

\begin{abstract}
Background Anxiety disorders are common comorbidities in children and adolescents with attention-deficit/hyperactivity disorder (ADHD) who are also at a high risk of bullying behavior. However, little is known about the roles of anxiety symptomatology in the relationship between ADHD and bullying behavior.

Objective This cross-sectional, clinic-based study aims to investigate the associations between anxiety symptomatology and bullying involvement in youth with ADHD.

Method One hundred and eighty children and adolescents with ADHD aged 10-18 years participated in the study. The Screen for Child Anxiety-Related Emotional Disorders (SCARED) was self-rated, and the participants were interviewed with the Revised Olweus Bully/Victim Questionnaire to categorize bullying involvement. Data were analyzed through percentage, nonparametric statistics, chi-squared statistics, and logistic regression analysis.

Results Sixty-nine percent of youth with ADHD reported involvement in bullying, of which $33.3 \%, 8.9 \%$, and $27.2 \%$ were classified as victims, bullies, and bully-victims, respectively. The means and $95 \%$ confidence intervals of the total SCARED scores showed a significant difference among bullying behavior groups. The highest SCARED scores could be noticed in the victim and bully-victim groups, with the lowest scores observed in the bully group. Youth with ADHD who had comorbid anxiety were 3.51 times more likely to be bullied than those who did not have anxiety.

Conclusions A differential effect of anxiety symptomatology on bullying behavior in youth with ADHD was evident. These results highlight the utility of including anxiety in the conceptualization of bullying problems in youth with ADHD to plan successful anti-bullying interventions.
\end{abstract}

Keywords Attention-deficit/hyperactivity disorder $\cdot$ Anxiety $\cdot$ Bullying $\cdot$ Victimization

Nuttorn Pityaratstian

drnuttorn@yahoo.com; nuttorn.p@chula.ac.th

Jirada Prasartpornsirichoke

pjirada18@gmail.com; jirada.pr@chula.ac.th

1 Department of Psychiatry, Faculty of Medicine, Chulalongkorn University, 1873 Rama IV Road, Pathumwan, Bangkok 10330, Thailand 


\section{Background}

Attention-deficit/hyperactivity disorder (ADHD) is a neurodevelopmental disorder with a typical onset in childhood, with a pattern of inattentive-hyperactive/impulsive symptoms across multiple settings that is inappropriate to the developmental stage and impairs psychosocial functioning (American Psychiatric Association, 2013). The worldwide prevalence estimates of ADHD in children and adolescents are approximately 5.29\%, with a relatively stable community prevalence in the past 30 years (Polanczyk \& Rohde, 2007; Polanczyk et al., 2014). A longitudinal study of children revealed high rates of academic difficulties, including grade retention, failure to graduate from secondary school, and low academic performances and achievements (Galera et al., 2009).

ADHD is often found to be highly comorbid with other disorders, with externalizing disorders, especially oppositional defiant disorder (ODD) and conduct disorder (CD), more frequently reported than internalizing disorders (Jensen et al., 1997). Anxiety disorders are comorbid with ADHD in about one-fourth of children in the general population and $30 \%-40 \%$ of children with ADHD in clinical settings (Biederman et al., 1991; Jensen et al., 1997; MTA Cooperative Group, 1999; Tannock, 2009). The presence of anxiety in children with ADHD may impact symptom expressions, although the findings to date have been inconsistent. In the National Institute of Mental Health Collaborative, Multisite Multimodal Treatment Study of Children with ADHD (MTA), 33\% of 579 children with ADHD also had comorbid anxiety disorders, with symptoms of inattention much more pronounced than hyperactivity or impulsivity. Teachers' ratings also showed these children to be less impulsive than children with ADHD and comorbid ODD or CD (Jensen et al., 2001; Newcorn et al., 2001). However, when a subset of children with ADHD and comorbid anxiety disorders was observed in regular classroom settings, the differences in ADHD behaviors compared with those of children with ADHD only or ADHD with ODD or CD were not detected (Abikoff et al., 2002). In the MTA sample, anxiety was manifested more markedly by negative affect and disruptive behavior than by fearfulness, which was found in typically developing children (Jensen et al., 2001). ADHD was found to intensify symptoms such as inattention and working memory deficits (Pliszka et al., 1999; Schatz \& Rostain, 2006; Tannock, 2009). Neuropsychological functioning characteristics have shown that anxiety in ADHD may partially inhibit impulsivity and response inhibition deficits (Schatz \& Rostain, 2006). Anxiety was found to moderate the relationship between ADHD and executive functioning $(\mathrm{EF})$ by which increased inattention was associated with worse EF, and increased ADHD symptoms were associated with worse EF only for those with high levels of anxiety (Castagna et al., 2019). Two pathways were hypothesized to explain the association between ADHD and anxiety. One involved early regulatory deficits in combination with high anxiety, whereas the other proposed that ADHD may be the secondary result of high anxiety (Nigg et al., 2004). Differential treatment response to behavioral treatment for children with ADHD and anxiety was also reported. Children with ADHD and anxiety disorders responded equally well to children with ADHD only on the combination treatment of intensive behavioral inventions and medications. However, children with ADHD only or ADHD with externalizing disorders (ODD/CD, without anxiety disorders) responded best to medication treatments (with or without behavioral treatments) (March et al., 2000; MTA Cooperative Group, 1999).

Children and adolescents with ADHD are at a higher risk of exhibiting bullying behavior (Holmberg \& Hjern, 2008; Verlinden et al., 2015) and experiencing victimization by peers in verbal, physical, and relational ways than typically developing youth 
(Kumpulainen et al., 2001; Schoeler et al., 2019; Sciberras et al., 2012; Wiener \& Mak, 2009). Bullying has been defined as a repeated negative activity or an aggression intended to harm or disturb someone who is perceived as being physically or psychologically inferior to the aggressor (Olweus, 2001; Smith et al., 2001). The prevalence rates for bullying vary enormously across studies, with $2-33 \%$ of students reporting being bullied by peers and 1-36\% admitting to bullying others (Currie, 2012; Hymel \& Swearer, 2015). A recent survey of students in Thailand and four other Southeast Asian countries reported 18.6\% of infrequent and $12.0 \%$ of frequent bullying victimization in the past month (Pengpid \& Peltzer, 2019). Cross-cultural surveys revealed that males are typically involved in more bullying behavior than females, as perpetrators and victims (Smith et al., 2019). School bullying usually peaks during the middle school and declines in high school (Bauer, 2008). The three categories of those who become involved in bullying at school are bully, victim, and bully-victim (those who engage in bullying as victims and bullies) (Hymel \& Swearer, 2015). Victim and bully are more likely than uninvolved counterparts to experience mental health problems, such as depression and anxiety (Hawker \& Boulton, 2000; Kaltiala-Heino et al., 1999; Menesini et al., 2009; Salmon et al., 1998), low self-esteem (Nansel et al., 2001), suicidal behaviors (Brunstein Klomek et al., 2007; Kim \& Leventhal, 2008), and violent behaviors (Nansel et al., 2003; Sourander et al., 2007a, 2007b; Sourander et al., 2011). The risk is found to be even greater in bully-victims who exhibit the highest level of internalizing and externalizing problems among all children involved in bullying (Arseneault et al., 2010; Juvonen et al., 2003; Menesini et al., 2009).

Several mechanisms have been proposed to explain the strong association between ADHD and bullying behavior, including the severity of ADHD symptoms (Kawabata et al., 2012), poor emotion regulation (Sofia et al., 2005), lack of social skills and emotion recognition (Murray-Close et al., 2014), and low self-esteem and increased sense of loneliness (Oldehinkel et al., 2007). All the factors can create a vicious cycle whereby youth with ADHD react as a perpetrator in a negative feedback loop (Swearer \& Hymel, 2015). The moderating roles of several factors in the bullying pattern in children with ADHD have been reported. Girls with ADHD are more likely than boys to be victimized and less likely to be perpetrators (Elkins et al., 2011; Novik et al., 2006). Likewise, ADHD symptoms are more strongly associated with being bullied in girls and with bullying others in boys (Bacchini et al., 2008; Sciberras et al., 2012). Adolescents with ADHD in the younger age group reported more serious bullying victimization than the older age group (Chou et al., 2018). With regard to comorbidities, adolescents with ADHD with comorbid ODD and $\mathrm{CD}$ in high school are at higher risks of perpetration and victimization (Fite et al., 2014; Holmberg \& Hjern, 2008), although a recent study conducted in clinical samples showed no significant relationship between ODD/CD and bullying involvement (Chou et al., 2018). Similarly, children with autism spectrum disorder (ASD) and ADHD increased odds of bullying involvement even after controlling for age and gender, whereas children with ASD who did not have ADHD were not at a greater risk of bullying than the general population (Montes \& Halterman, 2007).

Does having anxiety symptoms or disorders impact the associations between ADHD and bullying involvement? Theoretically, this is possible because of several potential mechanisms. On the perpetrator side, the presence of anxiety in youth with ADHD can dampen the expression of hyperactivity and impulsivity symptoms (Newcorn et al., 2001; Quay, 1997; Tannock, 2009), which can hypothetically lessen the chance of them exhibiting disruptive and bullying behaviors. On the contrary, youth with ADHD and comorbid anxiety disorders may be more prone to peer victimization due to shyness and social functioning impairment (Becker et al., 2015). Youth with ADHD may also be more likely to develop 
anxiety disorders as a result of their bullying involvement. The complex associations among ADHD, anxiety symptomatology, and bullying involvement warrant exploration but to date, research on the roles of anxiety symptomatology in the relationship between ADHD and bullying behavior is scarce. One study involving a community sample of 131 adolescents with ADHD revealed significant positive associations between anxiety and physical, relational, and reputational victimization (Becker et al., 2017). Another study on 287 adolescents aged 11-18 years, who were recruited from child and adolescent psychiatric outpatient clinics, showed that adolescents who were bullying victims reported more severe anxiety and depressive symptoms, whereas those with ADHD who bullied others reported more severe depressive symptoms (Hu et al., 2016). A recent meta-analysis indicated that children with ADHD and anxiety were not perceived differently from children with ADHD only; however, anxiety symptoms were associated with increased experiences of peer rejection (Bishop et al., 2019).

The aims of this present study were: (1) to examine the prevalence of bullying involvement in a sample of children and adolescents with ADHD, with and without anxiety symptomatology and (2) to investigate the associations between bullying involvement and anxiety symptomatology in children and adolescents with ADHD. We hypothesized that the prevalence of bullying involvement in our sample would be in line with studies in other settings and that the groups of victim and bully-victim would be associated with anxiety symptomatology more than the bully and the uninvolved.

\section{Method}

\section{Participants}

Participants were recruited from a child and adolescent psychiatric outpatient clinic at King Chulalongkorn Memorial Hospital, Bangkok, Thailand. Children and adolescents aged between 10 and 18 years, who had received a diagnosis of ADHD, and their parents were invited to participate by the study team during a regular follow-up visit at the clinic. The diagnosis of ADHD had been conducted by child and adolescent psychiatrists at the clinic independent to the study team according to the Diagnostic and Statistical Manual of Mental Disorders, 5th Edition (American Psychiatric Association, 2017). ADHD was diagnosed at the clinic by multiple informant approach, including (a) parent(s) interview, (b) child interview and behavioral observation, (c) parent rating of the short version of the Swanson, Nolan, and Pelham Version IV Scale (SNAP-IV) - Thai version, and (d) school report form and the SNAP-IV teacher version. The invitation to participate in the study was given to cases that were considered "stable" on the treatment regimen, defined by no significant change in ADHD symptoms, medication dosage, and psychosocial interventions in the past three months. Children and adolescents who had psychotic disorders, bipolar disorder, and intellectual disability or learning disorder, which impaired the understanding of the study purpose or the ability to complete the questionnaires, were excluded. A total of 180 children and adolescents diagnosed with ADHD and their parents were included to participate in this study. All the participants who gave consent to participate were asked to complete the questionnaires during their follow-up visit. All the participants and their parents received psychoeducation about ADHD, anxiety disorders, and bullying after the participation. Participants who scored above the cut-off threshold of anxiety symptomatology and bullying involvement were offered psychosocial interventions. The data collection 
was conducted between September 2018 and May 2019. The Institutional Review Board of Faculty of Medicine, Chulalongkorn University approved the study.

\section{Measures}

The Revised Olweus Bully/Victim Questionnaire (R-OBVQ) (Olweus, 1996) consists of 40 ordinal items, which measure perpetration/victimization related to seven specific forms of bullying (verbal, exclusion, physical, spreading false rumors, personal items stolen/damaged, threats/coercion, and harassment related to race). The respondents are also asked about the frequent location and severity of bullying incidents and the attitudes and reactions of teachers, peers, and parents to what happened to them. The R-OBVQ is rated according to two primary domains of "being victimized" and "bullying others" and scored according to a five-point Likert scale of (1) did not occur, (2) took place once a week, (3) occurred two or three times a month, (4) took place about once a week, and (5) occurred several times a week. Response can then be used to classify each respondent as uninvolved, victim, bully, and bully-victim (Olweus, 2007). The results of a previous study examining the psychometrics of the R-OBVQ were reported elsewhere and supported that the R-OBVQ has good reliability and validity (Bendixen \& Olweus, 1999; Kyriakides et al., 2006; Lee \& Cornell, 2009; Olweus, 1996, 2007; Price et al., 2013). Reliabilities of R-OBVQ were reported as Cronbach's Alpha of $0.83-0.85$ for "being victimized" and $0.76-0.87$ for "bullying others" (Gonçalves et al., 2016; Price et al., 2013). In this study, we used self-reporting for the questions "How often have you been bullied at school in the past couple of months?" and "How often have you taken part in bullying another student at school in the past couple of months?" A frequency of "two or three times a month" or more often is used as a cut-off for estimating bullying involvement prevalence (Solberg \& Olweus, 2003).

Screen for Child Anxiety-Related Emotional Disorders (SCARED) is a 41-item, child and parent self-report instrument used to screen for childhood anxiety disorders, including panic disorder/somatic symptoms, generalized anxiety disorder (GAD), separation anxiety disorder, social anxiety disorder, and school phobia (Birmaher et al., 1997, 1999). The severity of symptoms is rated for the past three months by using a zero- to two-point rating scale with 0 meaning not true or hardly ever true, 1 meaning sometimes true, and 2 meaning true or often true. SCARED is found to reliably discriminate between children with anxiety versus non-anxiety disorders in clinical settings, including individual types of anxiety disorders (Monga et al., 2000). The child and parent versions of SCARED have moderate parent-child agreement and good internal consistency (Cronbach's alpha $=0.90$ ), test-retest reliability, and discriminant validity and are sensitive to treatment response (Birmaher et al., 1999; Monga et al., 2000). In this study, the cut-off score of 30 was used to indicate the presence of anxiety, and the cut-off scores of 7, 9, 5, 8, and 3 were used to indicate the presence of panic/somatic symptoms, generalized anxiety, separation anxiety, social anxiety, and school phobia, respectively (University of Pittsburgh, 2021).

SNAP-IV (Swanson et al., 1999; Swanson et al., 2001) is a 26-item instrument completed by parents and teachers that measures the core symptoms of ADHD and ODD consistent with the Diagnostic and Statistical Manual of Mental Disorders (American Psychiatric Association, 1995). It consists of the domains of inattention and hyperactivity/impulsivity of the criteria for ADHD and oppositional symptoms of the criteria for ODD. Each item is rated on a four-point rating scale from 0 (not at all) to 3 (very much). SNAP-IV is a widely used clinical and research tool, which has been used extensively to screen and assess baseline symptoms (Swanson et al., 1999), track the progress of treatments in clinical settings, 
and determine treatment outcomes in research trials (Abikoff et al., 2005; Correia Filho et al., 2005; Jensen, 1999; Steele et al., 2006; Wigal et al., 2004), including being used as the primary outcome measure for the MTA study (MTA Cooperative Group, 1999). The Thai version of SNAP-IV shows good validity and reliability as a screening instrument of ADHD in clinical samples (Pityaratstian et al., 2014). In this study, the parents of the participants were asked to rate their child's current symptoms. The cut-off scores of 16, 13, and 15 were used to indicate the clinical significance level of the inattention, hyperactivity/ impulsivity, and oppositional defiant domain, respectively.

\section{Procedure and Statistical Analysis}

Children and their parents who gave consent to participate completed the questionnaires during their regular follow-up visit at the clinic. A research assistant then performed the interview on the basis of the R-OBVQ to collect data from the participants. The prevalence rates of children and adolescents with ADHD who were involved in each type of bullying behavior were calculated by percentage. Differences between groups in terms of age, SNAP-IV scores, and SCARED scores were calculated via nonparametric statistics. Chisquared statistics and logistic regression analysis were conducted to calculate the associations between bullying behavior and presence/absence of anxiety. All statistical analyses were performed using IBM SPSS software, version 22.

\section{Results}

Of the initial 221 children and adolescents with ADHD and their parents who consented to participate in the study, 41 were excluded due to incomplete data. The final sample consisted of 180 subjects with a mean age of $12.79 \pm 2.24$ years, including $146(81.1 \%)$ males and $34(18.9 \%)$ females. The mean duration of the participants who had been in treatment prior to enrolling in the study was $3.43 \pm 1.59$ years. The excluded group did not significantly differ from the studied group in terms of demographic characteristics.

\section{Bullying Behavior}

A total of 125 children and adolescents with ADHD (69.4\%) reported involvement in bullying, of which $33.3 \%, 8.9 \%$, and $27.2 \%$ were classified as victims, bullies, and bully-victims, respectively. Table 1 depicts the distribution of sample according to bullying behavior. No statistically significant difference was found between each group with regard to inattention and hyperactivity/impulsivity domains of ADHD. Significant group difference was found with regard to oppositional defiant symptoms domain.

\section{Anxiety Symptomatology}

According to SCARED scores, $49.4 \%$ of the sample had anxiety. The distribution of each type of anxiety includes panic/somatic symptoms (39.4\%), generalized anxiety (30\%), separation anxiety (55.6\%), social anxiety (26.1\%), and school phobia (32.8\%). In Table 2, significant group differences among bullying behavior groups were observed in the samples who had anxiety according to the cut-off score. Significant group differences among 


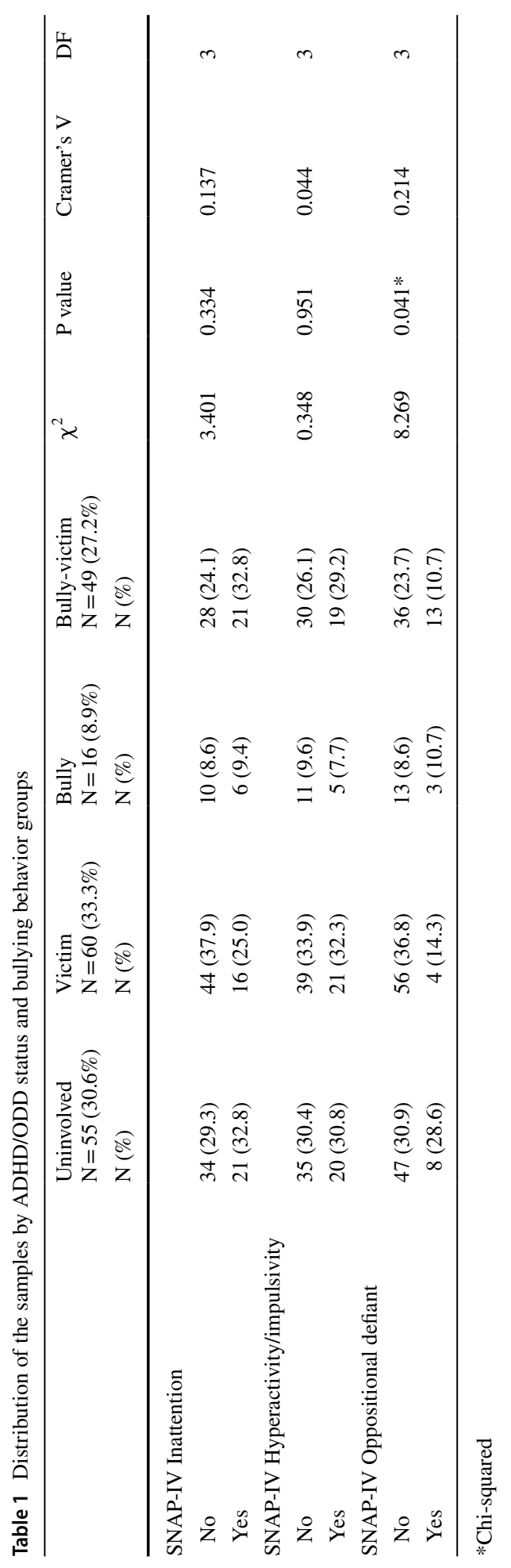




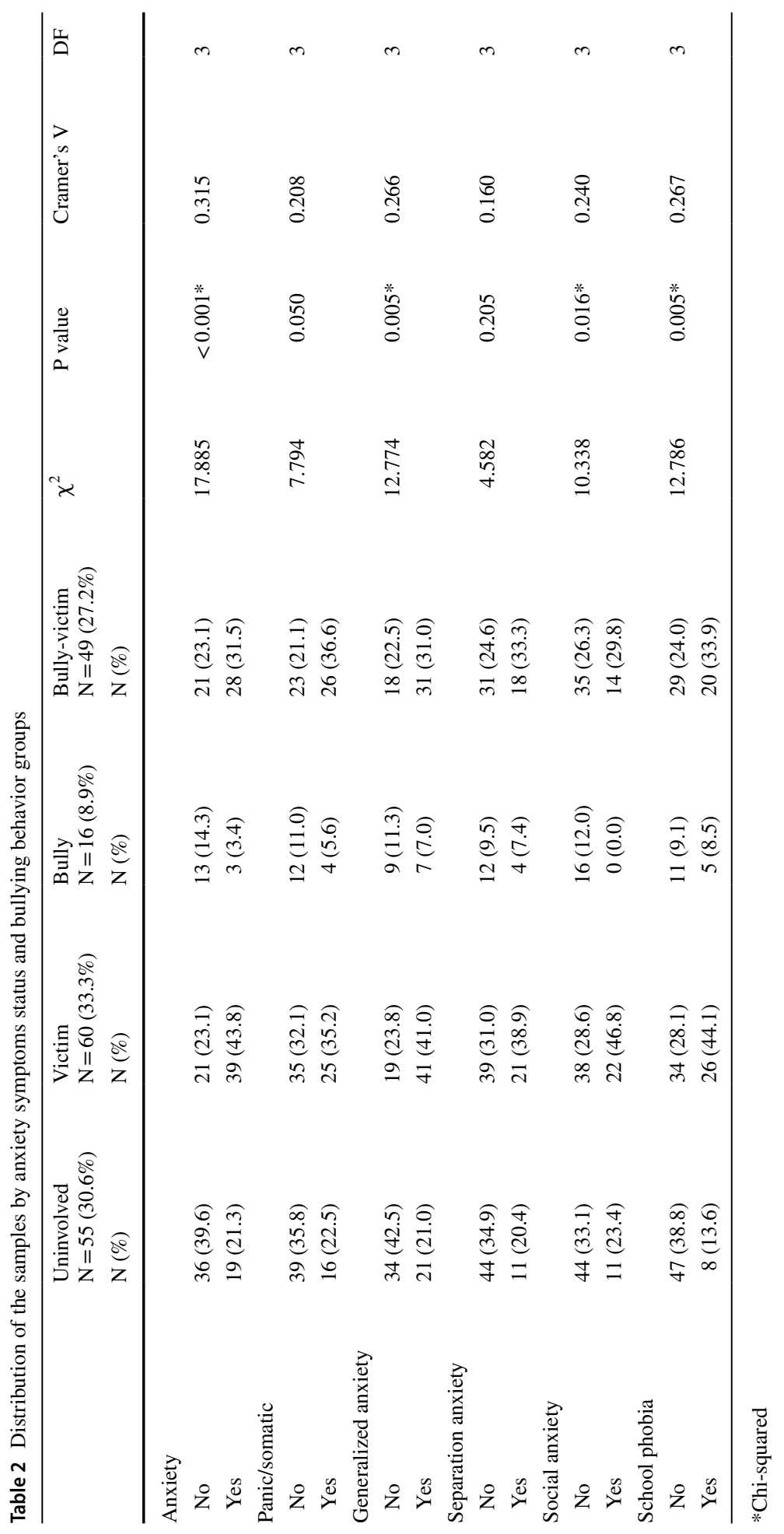


bullying behavior groups were also observed in the subscale domains of generalized anxiety, social anxiety, and school phobia.

\section{Anxiety and Bullying Behavior Associations}

Children and adolescents with ADHD from the victim group were significantly more likely than the bully, bully-victim and uninvolved groups to have anxiety, whereas those from the bully group were less likely than the victim, bully-victim and uninvolved groups to have anxiety. In the bully-victim group, a larger proportion of the sample had anxiety, but the difference was not statistically significant. The logistic regression analysis examining the associations of bullying victimization and anxiety symptomatology showed that children and adolescents with ADHD who had comorbid anxiety were 3.51 times more likely to be bullied than those who did not have anxiety (Odd ratio $[\mathrm{OR}]=3.51, B=1.26$, S.E. $=0.34$, Wald $=13.76, p=0.00$ ).

\section{Discussion}

This study provides the prevalence estimates of bullying behavior in children and adolescents with ADHD in the clinical setting. A total of $69.4 \%$ of children and adolescents reported involvement in bullying as victims (33.3\%), bullies (8.9\%), and bully-victims (27.2\%). Our results are comparable to a previous study conducted in nine- to 14-year-old children with ADHD by using the Bully/Victim Questionnaire (Craig, 1998), which found that $53.7 \%$ of the sample had involvement in bullying (26.9\% as victims, $17.3 \%$ as bullies, and $13.5 \%$ as bully-victims) (Wiener \& Mak, 2009). By contrast, a recent study in adolescents with ADHD in clinical settings revealed that only $28.6 \%$ were involved in bullying, and the authors hypothesized that clinical improvement from the treatment of ADHD may explain the difference in the bullying involvement among adolescents in clinical and community settings (Chou et al., 2018).

Our findings indicated that children and adolescents with ADHD involved in bullying behavior as victims or bully-victims had higher total SCARED scores than the bully and uninvolved groups. Anxiety symptomatology showed a differential effect on bullying behavior in children and adolescents with ADHD in which youth with ADHD who were victims were significantly more likely to have anxiety, whereas youth with ADHD who were bullies were less likely to have anxiety. Youth with ADHD who had comorbid anxiety were 3.51 times more likely to be bullied than those who did not have anxiety. Children and adolescents with ADHD were consistently found to experience higher rates of peer victimization than typically developing youth (Schoeler et al., 2019; Sciberras et al., 2012; Wiener \& Mak, 2009). Similarly, the association of anxiety and victimization is in line with previous studies, which reported that symptoms of anxiety are related to victimization in typically developed children (Bond et al., 2001; Craig, 1998; Espelage et al., 2001; Graham \& Juvonen, 1998; Isolan et al., 2013; Luukkonen et al., 2010; Wienke Totura et al., 2009). A recent survey of school children in five Southeast Asian countries found that bullying victimization is significantly associated with anxiety (Pengpid \& Peltzer, 2019). The relationship between bullying behavior and anxiety can be conceptualized as significant interpersonal stressors that lead to feelings of anxiety and distress, which, in turn, can perpetuate interpersonal problems (Degnan et al., 2010). The complex associations and crosssectional nature of this study preclude the interpretation of the causal relationship among 
victimization, anxiety, and ADHD. However, a substantial evidence supports the notion that higher levels of anxiety are associated with more problems related to social functioning in children and adolescents with ADHD (Becker et al., 2015; Biederman et al., 2013; Farmer et al., 2015; Humphrey et al., 2007; Karustis et al., 2000; Pollack et al., 2016). Comorbid anxiety in youth with ADHD is associated with poorer social skills, lower social competence, more social problems, less acceptance, more rejection, more ignoring by peers, and poorer relationships with parents and siblings (Bishop et al., 2019; Bowen et al., 2008; March et al., 2000; Mikami \& Pfiffner, 2008; Mikami et al., 2011). Difficulty in social functioning in youth with ADHD with comorbid anxiety can make them more susceptible to victimization, and when bullying happens, only a small number of peers would step in to defend them. On average, two to four peers are present in bullying incidents (O'Connell et al., 1999) with the majority of the time bystanders watching the incidents passively. Only $25 \%$ of the time that bystanders intervene on behalf of victims (Craig \& Pepler, 1998). Successful anti-bullying programs emphasize on encouraging bystanders to increase awareness of bullying, learn new skills to act in appropriate ways in bullying situations, and respond effectively in real-life situations (Kärnä et al., 2011; Mazzone, 2020), with peer support serving as a key component in school-based programs (Salmivalli et al., 2010). An impaired social functioning in children and adolescents with ADHD is possible, and comorbid anxiety can make bystanders reluctant to support and defend them. When bystanders become passive, this behavior could reinforce more bullying as it might be seen as a sign of approval by the perpetrators (Kärnä et al., 2011).

Children and adolescents with ADHD are at a high risk of exhibiting bully behavior (Holmberg \& Hjern, 2008; Verlinden et al., 2015). In our sample, however, those who were classified in the bully group were less likely to have comorbid anxiety. Youth with ADHD typically have peer problems related to intrusiveness, impulsivity, and aggressive behaviors (Erhardt \& Hinshaw, 1994). The presence of comorbid anxiety is found to be associated with less aggression and impulsivity among children with ADHD in some studies (Newcorn et al., 2001; Quay, 1997; Tannock, 2009). This can be seen as a potential mitigating factor for lessening disruptive behaviors and subsequent impact that would otherwise be present in youth with ADHD. Considering that aggression and impulsivity can strongly damage peer interactions of children with $\mathrm{ADHD}$, anxiety symptomatology may benefit peer relationship by reducing these aversive behaviors. Nonetheless, given that relationship problems cannot be conceptualized in a linear fashion, anxiety may create a cycle whereby anxious youth is more vulnerable to be bullied and over time may turn into bullies themselves. Swearer and Hymel (2015) argued for the multidirectionality of the socioecological diathesis-stress model and the influences of context to which individual factors can function anywhere in the chain of interactions as antecedents, contributing factors or consequences of involvement in bullying. In a twin study examining the association between peer victimization and child aggression, peer victimization was found to function as a diathesis for the development of aggression in children, even when genetic vulnerability was considered (Brendgen et al., 2008).

Of the five anxiety types measured by SCARED in our study, generalized anxiety, social anxiety, and school phobia were associated with bullying behavior in children and adolescents with ADHD. The link between social anxiety and peer victimization from previous studies was robust. Bullying victimization has been consistently linked with high levels of social anxiety (Blöte et al., 2015; Ranta et al., 2013; Siegel et al., 2009; Storch et al., 2003). Peer victimization predicts later levels of social anxiety in children, and this relationship is reciprocal whereby socially anxious children may ruminate about their worries and appear nervous during social interactions. Fear of negative social evaluation can make them avoid 
peer socialization and, as a result, the chance to learn essential social skills is hindered. This hindrance can contribute to more problems in interpersonal relationships and may place them at a greater risk of further victimization by their peers (Blöte \& Westenberg, 2007; Jacob et al., 2014; Siegel et al., 2009). The symptoms of social anxiety in early adulthood are associated with the relational peer victimization as recalled from the experience in the adolescent period (Dempsey \& Storch, 2008). Schneider et al. (2009) examined the psychosocial and behavioral concomitants of anxiety in boys with ADHD with and without chronic multiple tic disorder. They found that parent-reported social competence is associated with parent-reported social anxiety in children with ADHD (Schneider et al., 2009). Conversely, a positive peer relationship can be a key protective factor against peer victimization. The association between social anxiety and peer relationships is well-documented, with positive peer relationships consistently associated with low levels of social anxiety (Erath et al., 2007; La Greca \& Lopez, 1998). By the same token, difficulty making friends, being rejected and isolated, peer conflicts, and fear of being a victim of bullying have all been found to be related to school phobia and school refusal (Carroll, 2011; Havik et al., 2014; Kearney, 2008; Lyon \& Cotler, 2007; Thambirajah et al., 2008; Wilson et al., 2008). A study in youth with school refusal also indicates a third of the subjects are victims of bullying (Egger et al., 2003).

The link between generalized anxiety and bullying behavior is much less clear as the majority of the evidence has explored the association of bullying and anxiety in general (Copeland et al., 2013; Klomek et al., 2009; Sourander et al., 2007a, 2007b). A meta-analysis examining consequences of bullying victimization in childhood and adolescence found that those exposed to bullying victimization had an increased risk of developing GAD later in their lives ( $\mathrm{OR}=2.83$; 95\% CI: $1.38-5.84)$. However, only two data points were available for analysis to indicate this association (Moore et al., 2017). One possible explanation of the association between generalized anxiety and bullying victimization is that the latter may aggravate worry, which is the cardinal feature of GAD. Being bullied at school can make victims worried and apprehensive about the possibility of next bullying episodes. Poor regulation of worry is also associated with increased bully victimization, as those who exhibit uncontrollable worry can make them more vulnerable to future victimization (Hughes et al., 2009; Morelen et al., 2016).

The strengths of this study include the use of children and adolescents with ADHD in the clinical setting to examine potential differential associations between ADHD and bullying behavior, depending on the anxiety symptomatology status. The sample size is relatively large, and differential associations among different types of anxiety can be explored. However, the sample size in some groups (i.e., bully with anxiety) is small, and the interpretation should be cautious. A replication of our study in larger samples is clearly needed. Other limitations include the cross-sectional design, which makes the ascertainment of the directionality of relationships inconclusive. A longitudinal prospective study in youth with ADHD with and without anxiety disorders is more suitable to answer this question. The male: female ratio of 4.3:1 in this study is consistent with the male preponderance rates in ADHD samples from other studies (Franke et al., 2018; Owens et al., 2015). However, the generalization of the findings from the current research to female youth is limited due to the relatively small female sample. The term "anxiety symptomatology" in this study is operationalized as having symptoms above the cut-off scores measured by SCARED. Nonetheless, the dimensionality of the scale limits the interpretation. Measurement that targets the categorical diagnoses of anxiety disorders instead of anxiety symptoms can yield different results. Different types of informants of bullying behavior (parent, teacher, peer, and direct observations) can be used to explore the whole picture. Past research showed that children 
with different subtypes of ADHD differed significantly in their social behaviors (McQuade $\&$ Hoza, 2008). Future research should be conducted in different presentations or subtypes of youth with ADHD. Although our study collected data when the treatment regimen was stable, the contamination effect from the treatment could not be totally ruled out. Finally, studies on the mechanisms underpinning the relationships among ADHD, anxiety, and bullying behavior are crucial for devising and implementing proper interventions.

This study contributes to the limited literature examining the role of anxiety symptomatology in the association between youth with ADHD and bullying involvement. A number of key clinical implications have been made. First, the importance of clinicians carefully assessing for comorbid anxiety and bullying involvement in children and adolescents with ADHD is highlighted. When assessing youth with ADHD who have comorbid anxiety, clinicians should inquire about the possibility of bullying involvement, especially victimization. Moreover, the likely bidirectional relationship between ADHD and anxiety indicates the need for clinicians to consider anxiety management and anti-bullying interventions when working with this population. Children and adolescents with ADHD and comorbid anxiety can benefit from interventions, which aim to promote social skills and functioning. Investigating how to tailor interventions to meet the specific needs of youth with ADHD and anxiety is an important path for future research.

\section{Conclusions}

The study adds to the relatively limited evidence concerning associations between anxiety symptomatology and bullying behavior in children and adolescents with ADHD. A differential effect of anxiety in general and three specific types of anxiety (generalized anxiety, social anxiety, and school phobia) on bullying behavior in youth with ADHD were found. Children and adolescents with ADHD categorized as victims were significantly more likely to have anxiety, whereas those categorized as bullies were less likely to have anxiety. These results highlight the utility of including anxiety symptomatology in the conceptualization of bullying problems in youth with ADHD. Further studies that target underpinning mechanisms are needed to plan for effective anti-bullying interventions.

Acknowledgements The authors wish to express their sincere gratitude to the participants and their parents who made this study possible. Special gratitude is reserved for Dr. Warunya (Gib) Pongparadorn who helped enormously during the data collection process. Her tragic passing in October 2020 left us with broken hearts. However, she will be forever remembered and the memories about her will always be cherished.

Author Contributions NP contributed in conceptualizing and coordinating the study, and drafting and revising the manuscript. JP contributed in conceptualizing the study, collecting, entering, and analyzing data, and revising the manuscript. All authors read and approved the final manuscript.

Funding This research did not receive funding from any agency.

Data Availability All datasets used and analyzed in the current study are available on request from the study's first author (NP).

\section{Declarations}

Conflict of interest The authors declare that they have no competing interests.

Ethical Approval This study was approved by The Institutional Review Board of Faculty of Medicine, Chulalongkorn University (IRB No. 405/61; Date of approval: 27 Sep 2018). 
Consent to Participate Participation in this study was voluntary. Written consent was obtained from each participant and their parents taking part in this study.

Open Access This article is licensed under a Creative Commons Attribution 4.0 International License, which permits use, sharing, adaptation, distribution and reproduction in any medium or format, as long as you give appropriate credit to the original author(s) and the source, provide a link to the Creative Commons licence, and indicate if changes were made. The images or other third party material in this article are included in the article's Creative Commons licence, unless indicated otherwise in a credit line to the material. If material is not included in the article's Creative Commons licence and your intended use is not permitted by statutory regulation or exceeds the permitted use, you will need to obtain permission directly from the copyright holder. To view a copy of this licence, visit http://creativecommons.org/licenses/by/4.0/.

\section{References}

Abikoff, H. B., Jensen, P. S., Arnold, L. L., Hoza, B., Hechtman, L., Pollack, S., Martin, D., Alvir, J., March, J. S., Hinshaw, S., Vitiello, B., Newcorn, J., Greiner, A., Cantwell, D. P., Conners, C. K., Elliott, G., Greenhill, L. L., Kraemer, H., Pelham, W. E.,...Wigal, T. (2002). Observed classroom behavior of children with ADHD: Relationship to gender and comorbidity. Journal of Abnormal Child Psychology, 30(4), 349-359. https://doi.org/10.1023/a:1015713807297

Abikoff, H., McGough, J., Vitiello, B., McCracken, J., Davies, M., Walkup, J., Riddle, M., Oatis, M., Greenhill, L., Skrobala, A., March, J., Gammon, P., Robinson, J., Lazell, R., McMahon, D. J., Ritz, L., RUPP ADHD/Anxiety Study Group. (2005). Sequential pharmacotherapy for children with comorbid attention-deficit/hyperactivity and anxiety disorders. Journal of the American Academy of Child \& Adolescent Psychiatry, 44(5), 418-427. https://doi.org/10.1097/01.chi.0000155320.52322.37

American Psychiatric Association. (1995). DSM-IV : Diagnostic and statistical manual of mental disorders. American Psychiatric Association.

American Psychiatric Association. (2013). Diagnostic and statistical manual of mental disorders (5th ed.). American Psychiatric Association.

American Psychiatric Association. (2017). Diagnostic and statistical manual of mental disorders: DSM-5. American Psychiatric Association.

Arseneault, L., Bowes, L., \& Shakoor, S. (2010). Bullying victimization in youths and mental health problems: 'Much ado about nothing'? Psychological Medicine, 40(5), 717-729. https://doi.org/10.1017/ S0033291709991383

Bacchini, D., Affuso, G., \& Trotta, T. (2008). Temperament, ADHD and peer relations among schoolchildren: The mediating role of school bullying. Aggressive Behavior, 34(5), 447-459. https://doi.org/10. 1002/ab.20271

Bauer, L. (2008). Student victimization in U.S. schools : Results from the 2005 school crime supplement to the national crime victimization survey. U.S. Dept. of Education, National Center for Education Statistics, Institute of Education Sciences.

Becker, S., Langberg, J., Evans, S., Girio-Herrera, E., \& Vaughn, A. (2015). Differentiating anxiety and depression in relation to the social functioning of young adolescents with ADHD. Journal of Clinical Child \& Adolescent Psychology, 44(6), 1015-1029. https://doi.org/10.1080/15374416.2014.930689

Becker, S., Mehari, K., Langberg, J., \& Evans, S. (2017). Rates of peer victimization in young adolescents with ADHD and associations with internalizing symptoms and self-esteem. European Child and Adolescent Psychiatry, 26(2), 201-214. https://doi.org/10.1007/s00787-016-0881-y

Bendixen, M., \& Olweus, D. (1999). Measurement of antisocial behaviour in early adolescence and adolescence: Psychometric properties and substantive findings. Criminal Behaviour and Mental Health, $9(4), 323-354$.

Biederman, J., Faraone, S. V., Keenan, K., \& Tsuang, M. T. (1991). Evidence of familial association between attention deficit disorder and major affective disorders. Archives of General Psychiatry, 48(7), 633-642. https://doi.org/10.1001/archpsyc.1991.01810310051009

Biederman, J., Petty, C. R., Spencer, T. J., Woodworth, K. Y., Bhide, P., Zhu, J., \& Faraone, S. V. (2013). Examining the nature of the comorbidity between pediatric attention deficit/hyperactivity disorder and post-traumatic stress disorder. Acta Psychiatrica Scandinavica, 128(1), 78-87. https://doi.org/10. 1111/acps.12011 
Birmaher, B., Brent, D. A., Chiappetta, L., Bridge, J., Monga, S., \& Baugher, M. (1999). Psychometric properties of the screen for child anxiety related emotional disorders (SCARED): A replication study. Journal of the American Academy of Child \& Adolescent Psychiatry, 38(10), 1230-1236. https://doi. org/10.1097/00004583-199910000-00011

Birmaher, B., Khetarpal, S., Brent, D., Cully, M., Balach, L., Kaufman, J., \& Neer, S. M. (1997). The screen for child anxiety related emotional disorders (SCARED): Scale construction and psychometric characteristics. Journal of the American Academy of Child \& Adolescent Psychiatry, 36(4), 545-553. https://doi.org/10.1097/00004583-199704000-00018

Bishop, C., Mulraney, M., Rinehart, N., \& Sciberras, E. (2019). An examination of the association between anxiety and social functioning in youth with ADHD: A systematic review. Psychiatry Research, 273, $402-421$.

Blöte, A. W., Miers, A. C., \& Westenberg, P. M. (2015). The role of social performance and physical attractiveness in peer rejection of socially anxious adolescents. Journal of Research on Adolescence, 25(1), 189-200.

Blöte, A. W., \& Westenberg, P. M. (2007). Socially anxious adolescents' perception of treatment by classmates. Behaviour Research and Therapy, 45(2), 189-198.

Bond, L., Carlin, J. B., Thomas, L., Rubin, K., \& Patton, G. (2001). Does bullying cause emotional problems? A prospective study of young teenagers. BMJ, 323(7311), 480-484. https://doi.org/10.1136/ bmj.323.7311.480

Bowen, R., Chavira, D. A., Bailey, K., Stein, M. T., \& Stein, M. B. (2008). Nature of anxiety comorbid with attention deficit hyperactivity disorder in children from a pediatric primary care setting. Psychiatry Research, 157(1), 201-209. https://doi.org/10.1016/j.psychres.2004.12.015

Brendgen, M., Boivin, M., Vitaro, F., Girard, A., Dionne, G., \& Pérusse, D. (2008). Gene-environment interaction between peer victimization and child aggression. Development and Psychopathology, 20(2), 455-471. https://doi.org/10.1017/S0954579408000229

Brunstein Klomek, A., Marrocco, F., Kleinman, M., Schonfeld, I. S., \& Gould, M. S. (2007). Bullying, depression, and suicidality in adolescents. Journal of the American Academy of Child and Adolescent Psychiatry, 46(1), 40-49. https://doi.org/10.1097/01.chi.0000242237.84925.18

Carroll, H. (2011). The peer relationships of primary school pupils with poor attendance records. Educational Studies, 37(2), 197-206.

Castagna, P. J., Calamia, M., Roye, S., Greening, S. G., \& Davis, T. E. (2019). The effects of childhood inattention and anxiety on executive functioning: Inhibition, updating, and shifting. ADHD Attention Deficit and Hyperactivity Disorders, 11(4), 423-432. https://doi.org/10.1007/s12402-019-00306-7

Chou, W. J., Liu, T. L., Yang, P., Yen, C. F., \& Hu, H. F. (2018). Bullying victimization and perpetration and their correlates in adolescents clinically diagnosed with ADHD. Journal of Attention Disorders, 22(1), 25-34. https://doi.org/10.1177/1087054714558874

Copeland, W. E., Wolke, D., Angold, A., \& Costello, E. J. (2013). Adult psychiatric outcomes of bullying and being bullied by peers in childhood and adolescence. JAMA Psychiatry, 70(4), 419-426.

Correia Filho, A. G., Bodanese, R., Silva, T. L., Alvares, J. P., Aman, M., \& Rohde, L. A. (2005). Comparison of risperidone and methylphenidate for reducing ADHD symptoms in children and adolescents with moderate mental retardation. Journal of the American Academy of Child \& Adolescent Psychiatry, 44(8), 748-755. https://doi.org/10.1097/01.chi.0000166986.30592.67

Craig, W. (1998). The relationship among bullying, victimization, depression, anxiety, and aggression in elementary school children. Personality and Individual Differences, 24(1), 123-130.

Craig, W., \& Pepler, D. (1998). Observations of bullying and victimization in the school yard. Canadian Journal of School Psychology, 13(2), 41-59. https://doi.org/10.1177/082957359801300205

Currie, C. (2012). Social determinants of health and well-being among young people. Health Behaviour in School-Aged Children (HBSC) Study: International report from the 2009/2010 survey. Retrieved November 20, 2020, from http://www.euro.who.int/en/what-we-do/health-topics/Life-stages/childand-adolescent-health/publications/2012/social-determinants-of-health-and-well-being-amongyoung-people.-health-behaviour-in-school-aged-children-hbsc-study

Degnan, K. A., Almas, A. N., \& Fox, N. A. (2010). Temperament and the environment in the etiology of childhood anxiety. Journal of Child Psychology and Psychiatry, 51(4), 497-517.

Dempsey, A. G., \& Storch, E. A. (2008). Relational victimization: The association between recalled adolescent social experiences and emotional adjustment in early adulthood. Psychology in the Schools, 45(4), 310-322. https://doi.org/10.1002/pits.20298

Egger, H. L., Costello, J. E., \& Angold, A. (2003). School refusal and psychiatric disorders: A community study. Journal of the American Academy of Child \& Adolescent Psychiatry, 42(7), 797-807.

Elkins, I. J., Malone, S., Keyes, M., Iacono, W. G., \& McGue, M. (2011). The impact of attention-deficit/ hyperactivity disorder on preadolescent adjustment may be greater for girls than for boys. Journal of 
Clinical Child and Adolescent Psychology, 40(4), 532-545. https://doi.org/10.1080/15374416.2011. 581621

Erath, S. A., Flanagan, K. S., \& Bierman, K. L. (2007). Social anxiety and peer relations in early adolescence: Behavioral and cognitive factors. Journal of Abnormal Child Psychology, 35(3), 405-416.

Erhardt, D., \& Hinshaw, S. P. (1994). Initial sociometric impressions of attention-deficit hyperactivity disorder and comparison boys: Predictions from social behaviors and from nonbehavioral variables. Journal of Consulting and Clinical Psychology, 62(4), 833.

Espelage, D. L., Bosworth, K., \& Simon, T. R. (2001). Short-term stability and prospective correlates of bullying in middle-school students: An examination of potential demographic, psychosocial, and environmental influences. Violence and Victims, 16(4), 411-426. https://doi.org/10.1891/0886-6708. 16.4 .411

Farmer, C. A., Brown, N. V., Gadow, K. D., Arnold, L. E., Kolko, D. G., Findling, R. L., Molina, B. S., Buchan-Page, K. A., Rice, R. R., Jr., Bangalore, S. S., Bukstein, O., Rundberg-Rivera, E. V., McNamara, N., \& Aman, M. G. (2015). Comorbid symptomatology moderates response to risperidone, stimulant, and parent training in children with severe aggression, disruptive behavior disorder, and attention-deficit/hyperactivity disorder. Journal of Child and Adolescent Psychopharmacology, 25(3), 213-224.

Fite, P. J., Evans, S. C., Cooley, J. L., \& Rubens, S. L. (2014). Further evaluation of associations between attention-deficit/hyperactivity and oppositional defiant disorder symptoms and bullying-victimization in adolescence. Child Psychiatry and Human Development, 45(1), 32-41. https://doi.org/10.1007/ s10578-013-0376-8

Franke, B., Michelini, G., Asherson, P., Banaschewski, T., Bilbow, A., Buitelaar, J. K., Cormand, B., Faraone, S. V., Ginsberg, Y., Haavik, J., Kuntsi, J., Larsson, H., Lesch, K. P., Ramos-Quiroga, J. A., Réthelyi, J. M., Ribases, M., \& Reif, A. (2018). Live fast, die young? A review on the developmental trajectories of ADHD across the lifespan. European Neuropsychopharmacology, 28(10), 1059-1088.

Galera, C., Melchior, M., Chastang, J. F., Bouvard, M. P., \& Fombonne, E. (2009). Childhood and adolescent hyperactivity-inattention symptoms and academic achievement 8 years later: The GAZEL Youth study. Psychological Medicine, 39(11), 1895-1906. https://doi.org/10.1017/S0033291709005510

Gonçalves, F. G., Heldt, E., Peixoto, B. N., Rodrigues, G. A., Filipetto, M., \& Guimarães, L. S. P. (2016). Construct validity and reliability of Olweus bully/victim questionnaire-Brazilian version. Psicologia: Reflexão e Crítica, 29(1), 27. https://doi.org/10.1186/s41155-016-0019-7

Graham, S., \& Juvonen, J. (1998). Self-blame and peer victimization in middle school: An attributional analysis. Developmental Psychology, 34(3), 587-599. https://doi.org/10.1037//0012-1649.34.3.587

Havik, T., Bru, E., \& Ertesvåg, S. K. (2014). Parental perspectives of the role of school factors in school refusal. Emotional and Behavioural Difficulties, 19(2), 131-153.

Hawker, D. S., \& Boulton, M. J. (2000). Twenty years' research on peer victimization and psychosocial maladjustment: A meta-analytic review of cross-sectional studies. Journal of Child Psychology and Psychiatry, 41(4), 441-455. https://doi.org/10.1111/1469-7610.00629

Holmberg, K., \& Hjern, A. (2008). Bullying and attention-deficit- hyperactivity disorder in 10-year-olds in a Swedish community. Developmental Medicine and Child Neurology, 50(2), 134-138. https://doi.org/ 10.1111/j.1469-8749.2007.02019.x

Hu, H.-F., Chou, W.-J., \& Yen, C.-F. (2016). Anxiety and depression among adolescents with attention-deficit/hyperactivity disorder: The roles of behavioral temperamental traits, comorbid autism spectrum disorder, and bullying involvement. The Kaohsiung Journal of Medical Sciences, 32(2), 103-109.

Hughes, P. P., Middleton, K. M., \& Marshall, D. D. (2009). Students' perceptions of bullying in Oklahoma public schools. Journal of School Violence, 8(3), 216-232. https://doi.org/10.1080/153882209029106 56

Humphrey, J. L., Storch, E. A., \& Geffken, G. R. (2007). Peer victimization in children with attention-deficit hyperactivity disorder. Journal of Child Health Care, 11(3), 248-260.

Hymel, S., \& Swearer, S. M. (2015). Four decades of research on school bullying: An introduction. American Psychologist, 70(4), 293-299. https://doi.org/10.1037/a0038928

Isolan, L., Salum, G. A., Osowski, A. T., Zottis, G. H., \& Manfro, G. G. (2013). Victims and bully-victims but not bullies are groups associated with anxiety symptomatology among Brazilian children and adolescents. European Child and Adolescent Psychiatry, 22(10), 641-648. https://doi.org/10.1007/ s00787-013-0412-z

Jacob, M. L., Suveg, C., \& Whitehead, M. R. (2014). Relations between emotional and social functioning in children with anxiety disorders. Child Psychiatry \& Human Development, 45(5), 519-532. https:// doi.org/10.1007/s10578-013-0421-7

Jensen, P. S. (1999). A 14-month randomized clinical trial of treatment strategies for attention-deficit/hyperactivity disorder. Archives of General Psychiatry, 56(12), 1073-1086. 
Jensen, P. S., Hinshaw, S. P., Kraemer, H. C., Lenora, N., Newcorn, J. H., Abikoff, H. B., March, J. S., Arnold, L. E., Cantwell, D. P., Conners, C. K., Elliott, G. R., Greenhill, L. L., Hechtman, L., Hoza, B., Pelham, W. E., Severe, J. B., Swanson, J. M., Wells, K. C., Wigal, T., \& Vitiello, B. (2001). ADHD comorbidity findings from the MTA study: Comparing comorbid subgroups. Journal of the American Academy of Child and Adolescent Psychiatry, 40(2), 147-158. https://doi.org/10.1097/ 00004583-200102000-00009

Jensen, P. S., Martin, D., \& Cantwell, D. P. (1997). Comorbidity in ADHD: Implications for research, practice, and DSM-V. Journal of the American Academy of Child and Adolescent Psychiatry, 36(8), 1065-1079. https://doi.org/10.1097/00004583-199708000-00014

Juvonen, J., Graham, S., \& Schuster, M. A. (2003). Bullying among young adolescents: The strong, the weak, and the troubled. Pediatrics, 112(6 Pt 1), 1231-1237. https://doi.org/10.1542/peds.112.6.1231

Kaltiala-Heino, R., Rimpela, M., Marttunen, M., Rimpela, A., \& Rantanen, P. (1999). Bullying, depression, and suicidal ideation in Finnish adolescents: School survey. BMJ, 319(7206), 348-351. https://doi. org/10.1136/bmj.319.7206.348

Kärnä, A., Voeten, M., Little, T. D., Poskiparta, E., Kaljonen, A., \& Salmivalli, C. (2011). A large-scale evaluation of the KiVa antibullying program: Grades 4-6. Child Development, 82(1), 311-330. https://doi.org/10.1111/j.1467-8624.2010.01557.x

Karustis, J. L., Power, T. J., Rescorla, L. A., Eiraldi, R. B., \& Gallagher, P. R. (2000). Anxiety and depression in children with ADHD: Unique associations with academic and social functioning. Journal of Attention Disorders, 4(3), 133-149. https://doi.org/10.1177/108705470000400301

Kawabata, Y., Tseng, W. L., \& Gau, S. S. (2012). Symptoms of attention-deficit/hyperactivity disorder and social and school adjustment: The moderating roles of age and parenting. Journal of Abnormal Child Psychology, 40(2), 177-188. https://doi.org/10.1007/s10802-011-9556-9

Kearney, C. A. (2008). School absenteeism and school refusal behavior in youth: A contemporary review. Clinical Psychology Review, 28(3), 451-471.

Kim, Y. S., \& Leventhal, B. (2008). Bullying and suicide. A review. International Journal of Adolescent Medicine and Health, 20(2), 133-154. https://doi.org/10.1515/ijamh.2008.20.2.133

Klomek, A. B., Sourander, A., Niemelä, S., Kumpulainen, K., Piha, J., Tamminen, T., Almqvist, F., \& Gould, M. S. (2009). Childhood bullying behaviors as a risk for suicide attempts and completed suicides: A population-based birth cohort study. Journal of the American Academy of Child \& Adolescent Psychiatry, 48(3), 254-261.

Kumpulainen, K., Räsänen, E., \& Puura, K. (2001). Psychiatric disorders and the use of mental health services among children involved in bullying. Aggressive Behavior: Official Journal of the International Society for Research on Aggression, 27(2), 102-110.

Kyriakides, L., Kaloyirou, C., \& Lindsay, G. (2006). An analysis of the revised Olweus bully/victim questionnaire using the Rasch measurement model. British Journal of Educational Psychology, 76(Pt 4), 781-801. https://doi.org/10.1348/000709905X53499

La Greca, A. M., \& Lopez, N. (1998). Social anxiety among adolescents: Linkages with peer relations and friendships. Journal of Abnormal Child Psychology, 26(2), 83-94.

Lee, T., \& Cornell, D. (2009). Concurrent validity of the Olweus bully/victim questionnaire. Journal of School Violence, 9(1), 56-73.

Luukkonen, A. H., Rasanen, P., Hakko, H., Riala, K., \& Workgroup, S.-. (2010). Bullying behavior in relation to psychiatric disorders and physical health among adolescents: A clinical cohort of 508 underage inpatient adolescents in Northern Finland. Psychiatry Research, 178(1), 166-170. https://doi.org/ 10.1016/j.psychres.2010.04.022

Lyon, A. R., \& Cotler, S. (2007). Toward reduced bias and increased utility in the assessment of school refusal behavior: The case for diverse samples and evaluations of context. Psychology in the Schools, 44(6), 551-565.

March, J. S., Swanson, J. M., Arnold, L. E., Hoza, B., Conners, C. K., Hinshaw, S. P., Hechtman, L., Kraemer, H. C., Greenhill, L. L., Abikoff, H. B., Elliott, L. G., Jensen, P. S., Newcorn, J. H., Vitiello, B., Severe, J., Wells, K. C., \& Pelham, W. E. (2000). Anxiety as a predictor and outcome variable in the multimodal treatment study of children with ADHD (MTA). Journal of Abnormal Child Psychology, 28(6), 527-541. https://doi.org/10.1023/a:1005179014321

Mazzone, A. (2020). Bystanders to bullying: An introduction to the special issue. International Journal of Bullying Prevention, 2(1), 1-5. https://doi.org/10.1007/s42380-020-00061-8

McQuade, J. D., \& Hoza, B. (2008). Peer problems in attention deficit hyperactivity disorder: Current status and future directions. Developmental Disabilities Research Reviews, 14(4), 320-324.

Menesini, E., Modena, M., \& Tani, F. (2009). Bullying and victimization in adolescence: Concurrent and stable roles and psychological health symptoms. Journal of Genetic Psychology, 170(2), 115-133. https://doi.org/10.3200/GNTP.170.2.115-134 
Mikami, A. Y., \& Pfiffner, L. J. (2008). Sibling relationships among children with ADHD. Journal of Attention Disorders, 11(4), 482-492.

Mikami, A. Y., Ransone, M. L., \& Calhoun, C. D. (2011). Influence of anxiety on the social functioning of children with and without ADHD. Journal of Attention Disorders, 15(6), 473-484.

Monga, S., Birmaher, B., Chiappetta, L., Brent, D., Kaufman, J., Bridge, J., \& Cully, M. (2000). Screen for child anxiety-related emotional disorders (SCARED): Convergent and divergent validity. Depression and Anxiety, 12(2), 85-91. https://doi.org/10.1002/1520-6394(2000)12:2\%3c85::AID-DA4\%3e3.0. $\mathrm{CO} ; 2-2$

Montes, G., \& Halterman, J. S. (2007). Bullying among children with autism and the influence of comorbidity with ADHD: A population-based study. Ambulatory Pediatrics, 7(3), 253-257. https://doi.org/10. 1016/j.ambp.2007.02.003

Moore, S. E., Norman, R. E., Suetani, S., Thomas, H. J., Sly, P. D., \& Scott, J. G. (2017). Consequences of bullying victimization in childhood and adolescence: A systematic review and meta-analysis. World Journal of Psychiatry, 7(1), 60.

Morelen, D., Southam-Gerow, M., \& Zeman, J. (2016). Child emotion regulation and peer victimization: The moderating role of child sex. Journal of Child and Family Studies, 25(6), 1941-1953. https:// doi.org/10.1007/s10826-016-0360-6

MTA Cooperative Group. (1999). Moderators and mediators of treatment response for children with attention-deficit/hyperactivity disorder: The multimodal treatment study of children with attention-deficit/hyperactivity disorder-The MTA Cooperative Group. Archives of General Psychiatry, 56(12), 1088 .

Murray-Close, D., Hoza, B., Hinshaw, S. P., Arnold, L. E., Swanson, J., Jensen, P. S., Hechtman, L., \& Wells, K. (2014). Developmental processes in peer problems of children with attention-deficit/ hyperactivity disorder in The Multimodal Treatment Study of Children With ADHD: Developmental cascades and vicious cycles-CORRIGENDUM. Development and Psychopathology, 26(1), 287-287. https://doi.org/10.1017/S0954579413000953

Nansel, T. R., Overpeck, M. D., Haynie, D. L., Ruan, W. J., \& Scheidt, P. C. (2003). Relationships between bullying and violence among US youth. Archives of Pediatrics and Adolescent Medicine, 157(4), 348-353. https://doi.org/10.1001/archpedi.157.4.348

Nansel, T. R., Overpeck, M., Pilla, R. S., Ruan, W. J., Simons-Morton, B., \& Scheidt, P. (2001). Bullying behaviors among US youth: Prevalence and association with psychosocial adjustment. JAMA, 285(16), 2094-2100. https://doi.org/10.1001/jama.285.16.2094

Newcorn, J. H., Halperin, J. M., Jensen, P. S., Abikoff, H. B., Arnold, L. E., Cantwell, D. P., Conners, C. K., Elliott, G. R., Epstein, J. N., Greenhill, L. L., Hechtman, L., Hinshaw, S. P., Hoza, B., Kraemer, H. C., Pelham, W. E., Severe, J. B., Swanson, J. M., Wells, K. C., Wigal, T., \& Vitiello, B. (2001). Symptom profiles in children with ADHD: Effects of comorbidity and gender. Journal of the American Academy of Child \& Adolescent Psychiatry, 40(2), 137-146. https://doi.org/10. 1097/00004583-200102000-00008

Nigg, J. T., Goldsmith, H. H., \& Sachek, J. (2004). Temperament and attention deficit hyperactivity disorder: The development of a multiple pathway model. Journal of Clinical Child and Adolescent Psychology, 33(1), 42-53. https://doi.org/10.1207/S15374424JCCP3301_5

Novik, T. S., Hervas, A., Ralston, S. J., Dalsgaard, S., Rodrigues Pereira, R., Lorenzo, M. J., \& Group, A. S. (2006). Influence of gender on attention-deficit/hyperactivity disorder in Europe-ADORE. European Child and Adolescent Psychiatry, 15(Suppl 1), I15-24. https://doi.org/10.1007/s00787-006-1003-Z

O'Connell, P., Pepler, D., \& Craig, W. (1999). Peer involvement in bullying: Insights and challenges for intervention. Journal of Adolescence, 22(4), 437-452. https://doi.org/10.1006/jado.1999.0238

Oldehinkel, A. J., Rosmalen, J. G. M., Veenstra, R., Dijkstra, J. K., \& Ormel, J. (2007). Being admired or being liked: Classroom social status and depressive problems in early adolescent girls and boys. Journal of Abnormal Child Psychology, 35(3), 417-427. https://doi.org/10.1007/s10802-007-9100-0

Olweus, D. (1996). Revised Olweus bully/victim questionnaire. British Journal of Educational Psychology. https://doi.org/10.1037/t09634-000

Olweus, D. (2001). Peer harassment: A critical analysis and some important questions. In S. Graham \& J. Juvonen (Eds.), Peer harassment in school: The plight of the vulnerable and victimized. The Guilford Press.

Olweus, D. (2007). The Olweus bullying questionnaire. Hazelden.

Owens, E. B., Cardoos, S. L., \& Hinshaw, S. P. (2015). Developmental progression and gender differences among individuals with ADHD. In R. A. Barkley (Ed.), Attention-deficit hyperactivity disorder: A handbook for diagnosis and treatment (pp. 223-255). The Guilford Press. 
Pengpid, S., \& Peltzer, K. (2019). Bullying victimization and externalizing and internalizing symptoms among in-school adolescents from five ASEAN countries. Children and Youth Services Review, 106, 104473. https://doi.org/10.1016/j.childyouth.2019.104473

Pityaratstian, N., Booranasuksakul, T., Juengsiragulwit, D., \& Benyakorn, S. (2014). ADHD screening properties of the Thai version of Swanson, Nolan, and Pelham IV scale (SNAP-IV) and strengths and difficulties questionnaire (SDQ). J Psychiatr Assoc Thailand, 59(2), 97-110.

Pliszka, S. R., Carlson, C. L., \& Swanson, J. M. (1999). ADHD with comorbid disorders: Clinical assessment and management. Guilford press.

Polanczyk, G., \& Rohde, L. (2007). Epidemiology of attention-deficit/hyperactivity disorder across the lifespan. Current Opinion in Psychiatry, 20(4), 386-392. https://doi.org/10.1097/YCO.0b013 e3281568d7a

Polanczyk, G., Willcutt, E., Salum, G., Kieling, C., \& Rohde, L. (2014). ADHD prevalence estimates across three decades: An updated systematic review and meta-regression analysis. International Journal of Epidemiology, 43(2), 434-442. https://doi.org/10.1093/ije/dyt261

Pollack, B., Hojnoski, R., DuPaul, G. J., \& Kern, L. (2016). Play behavior differences among preschoolers with ADHD: Impact of comorbid ODD and anxiety. Journal of Psychopathology and Behavioral Assessment, 38(1), 66-75. https://doi.org/10.1007/s10862-015-9497-7

Price, M., Chin, M. A., Higa-McMillan, C., Kim, S., \& Frueh, B. C. (2013). Prevalence and internalizing problems of ethnoracially diverse victims of traditional and cyber bullying. School Mental Health, 5(4), 183-191. https://doi.org/10.1007/s12310-013-9104-6

Quay, H. C. (1997). Inhibition and attention deficit hyperactivity disorder. Journal of Abnormal Child Psychology, 25(1), 7-13.

Ranta, K., Kaltiala-Heino, R., Fröjd, S., \& Marttunen, M. (2013). Peer victimization and social phobia: A follow-up study among adolescents. Social Psychiatry and Psychiatric Epidemiology, 48(4), 533-544.

Salmivalli, C., Kärnä, A., \& Poskiparta, E. (2010). From peer putdowns to peer support: A theoretical model and how it translated into a national anti-bullying program. Handbook of bullying in schools: An international perspective (pp. 441-454). Routledge/Taylor \& Francis Group.

Salmon, G., James, A., \& Smith, D. M. (1998). Bullying in schools: Self reported anxiety, depression, and self esteem in secondary school children. BMJ, 317(7163), 924-925. https://doi.org/10.1136/bmj.317. 7163.924

Schatz, D. B., \& Rostain, A. L. (2006). ADHD with comorbid anxiety: A review of the current literature. Journal of Attention Disorders, 10(2), 141-149.

Schneider, J., Gadow, K. D., Crowell, J. A., \& Sprafkin, J. (2009). Anxiety in boys with attention-deficit/ hyperactivity disorder with and without chronic multiple tic disorder. Journal of Child and Adolescent Psychopharmacology, 19(6), 737-748.

Schoeler, T., Choi, S. W., Dudbridge, F., Baldwin, J., Duncan, L., Cecil, C. M., Walton, E., Viding, E., McCrory, E., \& Pingault, J. B. (2019). Multi-polygenic score approach to identifying individual vulnerabilities associated with the risk of exposure to bullying. JAMA Psychiatry, 76(7), 730-738. https://doi.org/10.1001/jamapsychiatry.2019.0310

Sciberras, E., Ohan, J., \& Anderson, V. (2012). Bullying and peer victimisation in adolescent girls with attention-deficit/hyperactivity disorder. Child Psychiatry and Human Development, 43(2), 254-270. https://doi.org/10.1007/s10578-011-0264-z

Siegel, R. S., La Greca, A. M., \& Harrison, H. M. (2009). Peer victimization and social anxiety in adolescents: Prospective and reciprocal relationships. Journal of Youth and Adolescence, 38(8), 1096-1109.

Smith, P. K., López-Castro, L., Robinson, S., \& Görzig, A. (2019). Consistency of gender differences in bullying in cross-cultural surveys. Aggression and Violent Behavior, 45, 33-40. https://doi.org/10.1016/j. avb.2018.04.006

Smith, P. K., Morita, Y., Junger-Tas, J., Olweus, D., Catalano, R. F., Slee, P., \& Duncan, R. (2001). The nature of school bullying: A cross-national perspective. Contemporary Psychology., 46(3), 298.

Sofia, D., Lisbeth, H., \& Ann-Margret, R. (2005). ADHD symptoms and peer relations of children in a community sample: Examining associated problems, self-perceptions, and gender differences. International Journal of Behavioral Development, 29(5), 388-398.

Solberg, M. E., \& Olweus, D. (2003). Prevalence estimation of school bullying with the Olweus bully/victim questionnaire. Aggressive Behavior: Official Journal of the International Society for Research on Aggression, 29(3), 239-268.

Sourander, A., Brunstein Klomek, A., Kumpulainen, K., Puustjärvi, A., Elonheimo, H., Ristkari, T., Tamminen, T., Moilanen, I., Piha, J., \& Ronning, J. A. (2011). Bullying at age eight and criminality in adulthood: Findings from the Finnish Nationwide 1981 Birth Cohort Study. Social Psychiatry and Psychiatric Epidemiology, 46(12), 1211-1219. https://doi.org/10.1007/s00127-010-0292-1 
Sourander, A., Jensen, P., Rönning, J. A., Elonheimo, H., Niemelä, S., Helenius, H., Kumpulainen, K., Piha, J., Tamminen, T., Moilanen, I., \& Almqvist, F. (2007a). Childhood bullies and victims and their risk of criminality in late adolescence: The Finnish From a Boy to a Man study. Archives of Pediatrics and Adolescent Medicine, 161(6), 546-552. https://doi.org/10.1001/archpedi.161.6.546

Sourander, A., Jensen, P., Rönning, J. A., Niemelä, S., Helenius, H., Sillanmäki, L., Kumpulainen, K., Piha, J., Tamminen, T., Moilanen, I., \& Almqvist, F. (2007b). What is the early adulthood outcome of boys who bully or are bullied in childhood? The Finnish "From a Boy to a Man" study. Pediatrics, 120(2), 397-404.

Steele, M., Weiss, M., Swanson, J., Wang, J., Prinzo, R. S., \& Binder, C. E. (2006). A randomized, controlled effectiveness trial of OROS-methylphenidate compared to usual care with immediate-release methylphenidate in attention deficit-hyperactivity disorder. Canadian Journal of Clinical Pharmacology, 13(1), e50-e62.

Storch, E. A., Brassard, M. R., \& Masia-Warner, C. L. (2003). The relationship of peer victimization to social anxiety and loneliness in adolescence. Child Study Journal, 33(1), 1-19.

Swanson, J. M., Kraemer, H. C., Hinshaw, S. P., Arnold, L. E., Conners, C. K., Abikoff, H. B., Clevenger, W., Davies, M., Elliott, G. R., Greenhill, L. L., Hechtman, L., Hoza, B., Jensen, P. S., March, J. S., Newcorn, J. H., Owens, E. B., Pelham, W. E., Schiller, E., Severe, J. B.,..Wu, M. (2001). Clinical relevance of the primary findings of the MTA: Success rates based on severity of ADHD and ODD symptoms at the end of treatment. Journal of the American Academy of Child and Adolescent Psychiatry, 40(2), 168-179. https://doi.org/10.1097/00004583-200102000-00011

Swanson, J., Lerner, M., March, J., \& Gresham, F. (1999). Assessment and intervention for attention-deficit/ hyperactivity disorder in the schools. Lessons from the MTA study. Pediatric Clinics of North America, 46(5), 993-1009. https://doi.org/10.1016/s0031-3955(05)70168-1

Swearer, S. M., \& Hymel, S. (2015). Understanding the psychology of bullying: Moving toward a socialecological diathesis-stress model. American Psychological Association. https://doi.org/10.1037/ a0038929

Tannock, R. (2009). Attention-deficit/hyperactivity disorder with anxiety disorders. In T. E. Brown (Ed.), ADHD comorbidities: Handbook for ADHD complications in children and adults (pp. 125-170). American Psychiatric Pub.

Thambirajah, M., Grandison, K. J., \& De-Hayes, L. (2008). Understanding school refusal: A handbook for professionals in education, health and social care. Jessica Kingsley Publishers.

University of Pittsburgh. (2021). Instruments: Screen for child anxiety related emotional disorders (SCARED). Retrieved November 20, 2021, from https://www.pediatricbipolar.pitt.edu/sites/default/ files/Thai $\% 20$ Screen $\% 20$ for $\% 20$ Child $\% 20$ Anxiety $\% 20$ Related $\% 20$ Disorders $\% 20 \% 28$ SCARED $\% 29 \%$ 20Child\%20Version.pdf.pdf

Verlinden, M., Jansen, P. W., Veenstra, R., Jaddoe, V. W., Hofman, A., Verhulst, F. C., Shaw, P., \& Tiemeier, H. (2015). Preschool attention-deficit/hyperactivity and oppositional defiant problems as antecedents of school bullying. Journal of the American Academy of Child and Adolescent Psychiatry, 54(7), 571-579. https://doi.org/10.1016/j.jaac.2015.05.002

Wiener, J., \& Mak, M. (2009). Peer victimization in children with attention-deficit/hyperactivity disorder. Psychology in the Schools, 46(2), 116-131.

Wienke Totura, C. M., Green, A. E., Karver, M. S., \& Gesten, E. L. (2009). Multiple informants in the assessment of psychological, behavioral, and academic correlates of bullying and victimization in middle school. Journal of Adolescence, 32(2), 193-211. https://doi.org/10.1016/j.adolescence.2008. 04.005

Wigal, S., Swanson, J. M., Feifel, D., Sangal, R. B., Elia, J., Casat, C. D., Zeldis, J. B., \& Conners, C. K. (2004). A double-blind, placebo-controlled trial of dexmethylphenidate hydrochloride and d, 1-threomethylphenidate hydrochloride in children with attention-deficit/hyperactivity disorder. Journal of the American Academy of Child and Adolescent Psychiatry, 43(11), 1406-1414. https://doi.org/10.1097/ 01.chi.0000138351.98604.92

Wilson, V., Malcolm, H., Edward, S., \& Davidson, J. (2008). 'Bunking off': The impact of truancy on pupils and teachers. British Educational Research Journal, 34(1), 1-17.

Publisher's Note Springer Nature remains neutral with regard to jurisdictional claims in published maps and institutional affiliations. 